\title{
O PAPEL DAS FERRAMENTAS DIGITAIS NO LETRAMENTO ATRAVÉS DE NARRATIVAS FANFICTION
}

\author{
Patrícia da Silva Campelo Costa - PPGIE/ UFRGS - patricia.campelo@yahoo.com \\ Eliseo Berni Reategui - PPGIE/UFRGS - eliseoreategui@gmail.com
}

Resumo: Este trabalho tem por objetivo apresentar uma proposta de pesquisa que se dispõe a investigar como o letramento em língua estrangeira é possível através da utilização de ferramentas digitais que propiciem análise e produção coletiva do gênero textual fanfiction. O propósito é observar de que modo o ambiente digital pode ser um meio potencializador de aprendizagem através de tarefas apoiadas na utilização de um minerador de texto e de um editor de texto coletivo como recursos mediadores da produção escrita. Pretende-se investigar como aprendizes de língua estrangeira lidam, através dessas ferramentas digitais, com o processo de criação colaborativa de textos fanfiction. Desse modo, espera-se observar a utilização de ferramentas digitais que sustentem a produção textual, utilizando-se de um gênero característico da web, fanfiction, como proposta textual.

Palavras-chave: escrita cooperativa, mineração de texto, fanfiction.

\section{THE ROLE OF DIGITAL TOOLS IN THE LITERACY PROCESS THROUGH NARRATIVES FANFICTION}

\begin{abstract}
This paper aims at presenting a research proposal which is supposed to investigate how foreign language literacy can be fostered through the use of digital tools that provide analysis and collaborative production of a textual genre known as fanfiction. It is examined the way a task can promote literacy in the digital environment, supported by the following resources: a digital tool for collaborative text edition and a text mining tool. The goal is to examine how foreign language learners deal with the process of creating fanfictions collaboratively by using those digital means. The purpose, therefore, is to observe the use of digital tools which support text production, throughout the creation of a typical textual genre from the internet, fanfiction.
\end{abstract}

Keywords: cooperative writing, text mining, fanfiction

\section{Introdução}

A proposta deste trabalho é centrada na busca por tarefas em meio eletrônico que possam fomentar processos de letramento em língua estrangeira, a partir de atividades promotoras da ativa participação, compartilhamento e construção de conhecimento por parte do aluno. Desse modo, a pesquisa vem ao encontro de uma necessidade real de examinar o letramento que pode se estabelecer em meio digital, visto que as novas gerações de aprendizes tendem a estabelecer nesse ambiente boa parte de suas organizações sociais. Conforme Veen e Vrakking (2009), vivemos em um tempo no qual a geração Homo Zappiens, composta especialmente por pessoas nascidas a partir 
do final da década de 80, convive com diversos aparatos tecnológicos, caracterizando-se por ser "uma nova espécie que atua em uma cultura cibernética global com base na multimídia” (p. 30). Anteriormente, Prensky (2001) já havia utilizado o termo nativos digitais para definir essa geração que seria formada por falantes/usuários nativos da linguagem digital proposta pela internet e pelos vídeo-games. Ainda para Veen e Vrakking, hoje esses indivíduos podem "ter controle sobre o fluxo de informações, lidar com informações descontinuadas e com a sobrecarga de informações” e "comunicaremse e colaborarem em rede” (p. 12). Assim, a escola seria uma esfera analógica que tenta comportar sujeitos digitais. Por isso, de maneira a incorporar na sala de aula medidas pedagógicas que contemplem a utilização de meios eletrônicos no contexto escolar, é essencial que o professor atue como um intermediário entre os aprendizes, as tarefas e os recursos digitais.

Nessa pesquisa, o letramento é visto como um processo pelo qual a aprendizagem em língua estrangeira pode ocorrer a partir de práticas de leitura e de produção textual socialmente significativas, a partir das quais os autores e leitores de um texto têm oportunidade de compartilhar a criação escrita. Tendo como ponto de partida a leitura, análise e posterior produção de um gênero textual característico da internet (fanfiction) ${ }^{1}$, é observado o processo de letramento em língua estrangeira decorrente de tarefas focalizadas na utilização de duas ferramentas de apoio à escrita: SOBEK e ETC.

SOBEK é uma ferramenta capaz de extrair termos relevantes em documentos e encontrar os relacionamentos entre estes a partir de um processo conhecido como mineração de texto. Feldman e Sanger (2006) definem tal processo como um método de extração de informações relevantes em bases de dados não estruturadas, ou semiestruturadas. O sistema SOBEK, inicialmente proposto como ferramenta de apoio ao trabalho docente no acompanhamento da escrita colaborativa (Macedo et al., 2009), também foi empregado como instrumento para auxiliar os alunos no processo de produção textual. Por sua vez, o ETC é um editor de texto cujo objetivo é proporcionar um espaço para a escrita cooperativa/colaborativa a distância. Para tal, o ETC cria um espaço virtual para que usuários, dispersos geograficamente, possam construir um texto de forma síncrona ou assíncrona, disponibilizando ferramentas de apoio à comunicação e às negociações que permeiam o processo de escrita colaborativa (Macedo, 2009).

A ferramenta SOBEK está incorporada na mais recente versão do editor de texto coletivo, ETC, com o nome de Rede de Conceitos, rede que nessa pesquisa atuará como vetor de exame de textos-modelos que possam auxiliar a produção escrita do aluno. Assim, a proposta é promover a leitura e a análise de textos exemplificativos através dessa rede, incluída dentro do editor no qual os informantes da pesquisa poderão realizar uma produção colaborativa de narrativas. Desse modo, pretende-se formar um ciclo de criação de textos, a partir do qual os alunos cooperativamente baseiam seu processo de elaboração de narrativas, partindo da leitura e exame de fanfictions que servirão como modelo para a criação posterior de novos textos. Nesse circuito de tarefas que promovam a leitura e a produção, insere-se o objetivo deste trabalho, que tem como escopo analisar a promoção de letramento em ambiente digital, a partir de um fenômeno social da internet - a escrita e compartilhamento de fanfictions.

De modo a delimitar o tema dessa proposta de pesquisa, o objetivo é conduzir o estudo a partir das seguintes questões: a) De que maneira a ferramenta ETC, integrada à Rede de Conceitos (SOBEK), pode propiciar oportunidades de letramento em língua estrangeira? b) De que modo um ciclo que envolva leitura, análise e produção textual colaborativa (constituindo, assim, um letramento em língua estrangeira focado na leitura e produção textual) pode ser conduzido em ambiente digital? Destarte, além do 
propósito específico de investigar de que maneira esse processo cíclico de produção ocorre com o apoio das ferramentas, temos também o objetivo de fomentar uma reflexão acerca da influência do meio digital no processo de letramento.

\section{As ferramentas digitais}

Para o presente estudo, foi pensada a utilização do minerador de texto SOBEK, integrado ao editor de texto coletivo ETC. A Ferramenta SOBEK é capaz de identificar conceitos relevantes em um texto a partir da análise da frequência dos termos nesse material textual. Um algoritmo específico foi implementado na ferramenta, baseado em análises estatísticas dos textos e representação das informações extraídas em um modelo de grafo chamado de distância n-simples (Schenker, 2003).

A ferramenta opera da seguinte maneira:

(1) Copia-se o texto que se quer trabalhar para a área de entrada de dados da ferramenta. Alternativamente, carrega-se um texto em formato $t x t$, doc ou $p d f$.

(2) A partir desse texto, cria-se uma base de conceitos automaticamente através do processo de mineração de textos. Esses conceitos correspondem a um conjunto de palavras e termos que ocorrem com mais frequência no texto, excluindo-se artigos, preposições, e outras palavras consideradas sem significado relevante $^{2}$.

(3) Extraídos os conceitos, gera-se um grafo com os conceitos mais frequentes e seus relacionamentos. A figura 1 mostra um exemplo de grafo extraído para uma fanfiction baseada no filme Avatar ${ }^{3}$.

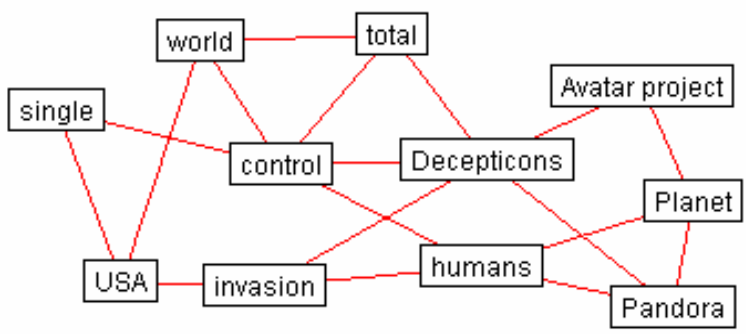

Figura 1 - Grafo gerado para uma fanfiction com a temática sobre o filme Avatar

A partir do exemplo, percebe-se que os termos extraídos estão efetivamente relacionados ao tema central do texto. É possível inclusive inferir possíveis frases a partir dos relacionamentos entre dois ou mais nodos do grafo. Observe, no entanto, que a idéia aqui não é reproduzir o texto original a partir dos grafos, mas sim instigar os estudantes a refletir sobre um tema, sobre um texto ou sobre suas próprias produções textuais.

Por sua vez, o editor de texto coletivo ETC, desenvolvido pelo NUTED da UFRGS, teve sua primeira versão desenvolvida em 2002 com o propósito de auxiliar a produção coletiva de textos em ambiente digital. Uma segunda versão, produzida em 2005, trouxe novas funcionalidades ao editor, que tornaram "possível o máximo de trocas de idéias entre os autores do texto, sem deixar de respeitar o tempo, a individualidade e os processos de cada um." ${ }^{4}$. Em 2009 novas atualizações foram realizadas, a fim de ser lançada uma nova versão do editor. Assim, as funcionalidades do ETC incluem: a) Documentos (pasta em que ficam disponibilizados os textos construídos pelo usuário, juntamente com colegas); b) Biblioteca (utilizada para uma possível inserção de 
material de apoio); c) Fórum; d) Dados Pessoais e e) Ajuda. Ao acessar a pasta Documentos, o usuário tem acesso ao grupo de textos do qual participa. As funcionalidades de navegação do ETC que se relacionam à produção de texto incluem, além do dispositivo de edição, na qual múltiplos autores podem interferir em um texto, uma opção de histórico, na qual todas as versões anteriores da produção ficam armazenadas. Além disso, o ETC tem a ferramenta SOBEK incorporada em sua estrutura, levando o nome de Rede de Conceitos, de modo que o aluno, a partir desse ícone, possa analisar grafos que representem seu texto.

\section{Letramento em ambiente digital}

Particularmente, procura-se examinar nessa pesquisa um processo que englobe etapas sustentadoras da produção textual do gênero fanfiction. Com essa análise, o escopo é investigar de que modo as ferramentas digitais de aprendizagem, juntamente com a proposta de tarefa sugerida através delas, podem contribuir para o letramento em língua estrangeira.

São incipientes os estudos na área de letramento em língua estrangeira (Schlatter, 2009), pois a maioria das pesquisas é focalizada na língua materna. Na presente pesquisa, um dos objetivos é examinar como a tecnologia educacional, a partir da proposta de tarefas envolvendo fanfiction em ferramentas digitais, pode auxiliar no processo de letramento. Partimos, então, de pesquisas que contemplam a produção colaborativa através de ferramentas de autoria coletiva (Costa, 2008; Behar et al., 2006), estudos que investigam o uso de ferramentas de mineração de texto na produção e avaliação textual (Macedo et al., 2009), assim como investigações sobre o papel das fanfictions na potencialização da aprendizagem (Black, 2009, 2007). Tendo como base esses trabalhos, a proposta aqui contempla a incorporação do conceito de letramento em língua estrangeira a partir da manipulação de fanfictions no ambiente digital, incluindo para tal processo ferramentas que propiciem um processo significativo da produção textual.

Lam (2000) enfatiza a importância da interação na aprendizagem, valendo-se do espaço computacional como ponto de partida, pois discute que os alunos, quando engajados em atividades interativas no meio digital, podem oferecer auxílio à atuação do outro. Para a autora, o letramento em uma segunda língua é entendido como um processo pelo qual os indivíduos se socializam através do pertencimento a um grupo e, em troca, participam na construção de práticas sociais dessas comunidades. Conforme a noção de práticas de letramento, a aprendizagem de língua estrangeira, então, se daria como prática social, de modo a requerer do aprendiz participação intensa de maneira colaborativa, a fim de compartilhar seu processo de aprendizado com os colegas. No trabalho aqui proposto focalizamos o letramento sob o ponto de vista da leitura e produção textual através da utilização de ferramentas digitais, e a partir desse conceito, o objetivo é proporcionar aos alunos uma maior participação nas redes complexas disponíveis pelo ambiente digital. Visto que o letramento pode ser definido como um "estado ou condição de quem não só sabe ler e escrever, mas exerce as práticas sociais de leitura e escrita que circulam na sociedade em que vive, conjugando-as com as práticas sociais de interação oral” (Soares, 1999), propomos um trabalho no qual o compartilhamento das produções textuais, através da escrita coletiva, está relacionado ao caráter colaborativo, participativo e inacabado do processo de escrever em ambiente digital. Com a utilização das ferramentas propostas, o objetivo é estabelecer um ciclo no 
qual os alunos promovam construções colaborativas, a fim de gerar uma prática social que pode se constituir no letramento em língua estrangeira, em ambiente digital.

De acordo com Clark (2000, p. 49), o "uso da linguagem é realmente uma forma de ação conjunta, que é aquela ação levada a cabo por um grupo de pessoas agindo em coordenação uma com a outra”. Além disso, para Waquil e Behar (2008), no espaço digital, o professor e o aluno "interagem na busca da construção cooperativa do saber e do conhecimento em rede, tornando-se, assim, parceiros no processo de aprendizagem" (p.147). Desse modo, a noção de linguagem que embasa este trabalho se relaciona à idéia de uso da língua como agir social, a partir do qual tarefas cooperativas podem se desenvolver em sala de aula a fim de integrar os indivíduos em instâncias de engajamento comunicativo e negociação de sentidos.

Através da inclusão dessas tarefas cooperativas, é proposto um trabalho que compreenda o dispositivo digital como um meio facilitador para a construção de novas relações de sentido. Assim, espera-se que o aluno intensifique seu processo de reflexão durante a realização colaborativa das etapas de elaboração textual, a fim de que seu próprio processo de aprendizagem seja repleto de construções e desconstruções de conceitos. Para Ramal (2002), o estabelecimento de novas relações de sentido seria possível através da inserção de textos não-lineares em sala de aula, que se caracterizam por conterem conexão de saberes, construção coletiva e subversão da atitude monológica. Broch (2008, p.36) também ressalta que a inserção do "computador por si só não gera mudança, mas as atividades/tarefas que promovem a interação e a construção de conhecimento conjunto, mediadas pelo computador, podem desencadear processos cognitivos”.

A pesquisa aqui proposta também espera desenvolver entre os alunos a noção de texto como gênero textual, com um propósito social, que valorize a reflexão e o senso crítico, focalizando o sentido e não apenas estruturas lingüísticas. Conforme Geraldi (1985, p.47), "na escola produzem-se redações, e não textos, isto é, a situação de produção do texto escolar é tão artificial que esse perde sua característica básica: o caráter interlocutório.” Em aulas tradicionais, o foco das produções parece ser justamente na avaliação de aspectos pontuais da gramática, enquanto que o estudo do gênero textual é ignorado. Moraes e Kleiman (1999) inclusive mencionam a necessidade de se trabalhar em língua estrangeira com gênero discursivos, a fim de transformar o processo de leitura em prática social, e assim estabelecer um processo de letramento.

\section{O fenômeno fanfiction}

Black (2006) expõe a noção de fanfiction como um gênero da internet baseado na escrita de narrativas por fãs de alguns dos ícones da cultura popular, que envolve seriados, filmes e animes (animação japonesa), por exemplo. $\mathrm{Na}$ produção de fanfictions, os autores/fãs, tendo como ponto de partida a história original, podem aumentar ou modificar o roteiro das histórias, acrescentar novos personagens e modificar as relações entre os já existentes. Apesar de fanfictions já existirem há anos na forma impressa (Jenkins, 1992), as novas TICs (Tecnologias de Informação e Comunicação) oferecem a esses fãs a oportunidade de terem encontros online durante os quais os autores e leitores-fãs podem escrever, trocar textos, criticar e discutir mudanças em suas fanfictions de maneira colaborativa (Black, 2006). Nesses momentos, os autores-fãs têm a chance de receber feedback de seus interlocutores leitores, escrever colaborativamente e interagir com grupos sociais afins. Os estudos de Black (2006, 2007, 2009) atestam a eficácia da utilização da escrita de fanfictions, visto 
que os informantes de suas pesquisas desenvolveram confiança e motivação para continuar a escrever devido ao interesse e andaimento fornecido por seus leitores. Esses resultados são condizentes com a opinião de Ramal (2002), a qual sustenta que a produção textual em suportes digitais impulsiona a escrita a uma nova fase, na qual os processos de cooperação e reconstrução serão essenciais.

Inclusive há na web um fenômeno conhecido como relay writing (Yi, 2008), a partir do qual os autores iniciam um texto e relay (redirecionam) essa produção a outros indivíduos, a fim de que um processo colaborativo de escrita na rede ocorra. Voltado às fanfictions, há um processo similar ao relay writing, conhecido como fanfiction role play (Black, 2009), através do qual uma narrativa pode ser composta por diversos fãs/escritores que revezam sua posição autoral ao criar uma história. Assim como em jogos de role-playing (RPG) diversos participantes assumem papéis de personagens, de modo a propor uma ficção coletiva no jogo, no fanfiction role play o objetivo também está centrado na criação participativa.

Podemos observar que novas formas de letramento digital afetam os processos de aprendizagem e participação social dos indivíduos, pois há influência de novas mídias e da tecnologia nos processos de escrita, interação e transposição de identidades no meio digital. Visto que há múltiplos territórios online, as identidades dos usuários dessas mídias se tornam policulturais, e a partir de práticas digitais significativas pode ocorrer a socialização, o uso e o desenvolvimento da linguagem. Com a incorporação da tecnologia como meio passível de construção de letramento, a idéia de conhecimento compartilhado se faz presente, já que o usuário constrói sua literacia a partir de práticas sociais. Além disso, pode haver ganho de confiança e competência por parte do indivíduo, quando há um reconhecimento sobre o seu papel de produtor de novas formas de letramento.

Black (2009) procurou examinar as práticas sociais e de letramento de três aprendizes de inglês em uma comunidade online de fanfiction. Tal estudo teve caráter etnográfico longitudinal, com duração de 3 anos, e se baseou na análise da influência da autoria de fanfictions no letramento dos aprendizes. A partir de tal pesquisa, Black observou que através da participação em práticas online, os aprendizes empregaram identidades transculturais, estabeleceram relações transnacionais e experimentaram novas práticas de letramento. Assim, vemos que a aquisição de letramento digital é possível através da participação em práticas sociais diversas e do pertencimento a comunidades online que possam promover o desenvolvimento lingüístico, tecnológico e social desse usuário. A partir dessa inclusão em comunidades digitais, os aprendizes adquirem papel ativo, visto que disseminam seus produtos simbólicos. Assim, o consumo de cultura é transformado em criações compartilhadas, que promovem uma recontextualização de mídias originais e permitem uma participação cooperativa. Partindo da idéia de colaboração, há uma mudança do paradigma de produção (em especial produção escrita), que tendia a se concentrar em um modelo individual e baseado na produção pelo especialista.

Lankshear e Knobel (2007) apresentam um estudo teórico com o objetivo de examinar o processo de letramento em mídias tecnológicas a partir de um viés sociocultural, focalizando, então, o vínculo com práticas sociais. É apresentado um panorama teórico sobre os conceitos de letramento e cultura de participação, além de ser discutido de que modo o consumo da cultura popular é transformado em produção no ambiente online. Nesse caso, o letramento é visto como um fenômeno que permite a aplicação de conhecimentos por parte do indivíduo, em contextos específicos de uso, para propósitos definidos. Assim, o letramento em meio digital se baseia nas noções de comunicação, socialização e auto-representação do indivíduo, que pode passar a ter suas múltiplas 
identidades reconhecidas na esfera midiática. Com isso, ocorre uma mudança nos paradigmas que estabelecem os papéis de autor/leitor e produtor/consumidor, visto que novos gêneros e participações online possibilitam uma prática socialmente significativa por parte dos interagentes.

\section{Procedimentos metodológicos}

A fim de investigar uma proposta de letramento em meio eletrônico, foram pensadas etapas que pudessem proporcionar ao aluno novos meios de produzir, compartilhar e interagir a partir da criação textual. As etapas para o processo de produção coletiva em ambiente digital estão contempladas a partir das seguintes fases:

a) insumo, a partir da escolha e leitura de fanfictions em sites de internet, com vistas a analisar posteriormente os textos escolhidos na Rede de Conceitos do ETC. A primeira etapa da investigação, que se constitui no insumo, embarca a fase de leitura de fanfictions, por parte dos alunos informantes. Nesse momento, os alunos têm a liberdade de escolher o tema da(s) narrativa(s) que pretendem ler e de qual site que disponha desse material planejam iniciar sua leitura, apesar de a página fanfiction.net (por conter o maior banco de dados desse gênero) ser uma sugestão. Nessa etapa de insumo, o aluno pode reconhecer características centrais do gênero, tais como a interferência forte do leitor no texto, visto que fanfictions tendem a ser publicadas em capítulos e o autor geralmente se embasa no feedback dos leitores para a continuação da história.

b) análise de textos exemplificativos, através da rede de conceitos integrada ao editor de texto ETC, de modo que o aluno possa examinar, através de grafos, as estruturas de fanfictions já disponibilizadas na web e escolhidas por ele como modelo, para que tais exemplos baseiem o formato de suas próprias narrativas. Após o insumo inicial, os alunos utilizam a ferramenta SOBEK, incluída no editor ETC, através da qual pode ser realizada uma extração de termos recorrentes em um texto e posterior construção de grafos. Essa ferramenta é utilizada na etapa posterior ao provimento de insumo, logo antes da produção textual. Conforme Klemann et al. (2009, p.2), a SOBEK é "uma ferramenta computacional capaz de extrair grafos a partir da captura dos principais termos utilizados nos textos e seus relacionamentos." Os textos a serem usados na SOBEK são modelos de fanfictions escolhidos pelo aluno, que após a leitura da(s) narrativa(s) inclui esse material na ferramenta a fim de que conceitos frequentes do texto sejam formatados em um grafo. Desse modo, o aluno pode perceber, por exemplo, a recorrência de tempos verbais característicos das narrativas, assim como a presença constante de adjetivos para caracterizar personagens e espaço. Portanto, a partir de uma mineração de texto, o aprendiz tem, como recurso para o draft (rascunho) de seu texto, modelos de grafos que podem auxiliar na estruturação de sua narrativa.

c) processo coletivo de produção de textos, através da ferramenta ETC, baseado na análise feita previamente da Rede de Conceitos, durante o qual os alunos podem construir cooperativamente narrativas fanfiction de sua própria autoria. É iniciado o processo de produção de textos por parte dos alunos, baseado na modelagem e na análise do grafo proveniente da fanfiction modelo. A ferramenta de escrita coletiva ETC é usada neste momento, a fim de oferecer um espaço para a criação colaborativa entre os agentes de construção do texto a ser publicado em um site de fanfictions, para que haja interlocução real com leitores desse gênero. Desse modo, o propósito da pesquisa é examinar de que maneira as referidas ferramentas digitais, juntamente 
com a incorporação de um gênero típico da internet, contribuem para o letramento em língua estrangeira. O procedimento acima explicitado é definido como cíclico, visto que parte da leitura (de um texto modelo) e retorna a essa etapa (com a leitura que novos interlocutores fazem dos textos publicados). Assim, o processo de composição textual em ambiente digital é cíclico, pois, além de ser colaborativo e significativo socialmente, nasce da leitura de fanfictions, parte para a análise de modelos e produção de novos textos coletivamente e, recursivamente, implica na leitura dos textos publicados.

Na figura 2 abaixo, por exemplo, temos um grafo decorrente de trechos iniciais de uma fanfiction baseada no seriado Vampire Diaries. ${ }^{5}$ Tal grafo foi construído a partir de alguns termos recorrentes dessa narrativa e representa a temática central do programa (história de vampiros). A partir do grafo, podemos observar a recorrência de alguns tempos verbais no passado simples (tempo verbal característico de narrativas), a presença de adjetivos para caracterizar os personagens, assim como elementos que estruturam o contexto da narrativa. Além disso, é possível perceber termos na língua estrangeira que ajudam a caracterização da temática do seriado, visto que, por exemplo, quase todas as expressões se relacionam à expressão smell of blood (cheiro de sangue).

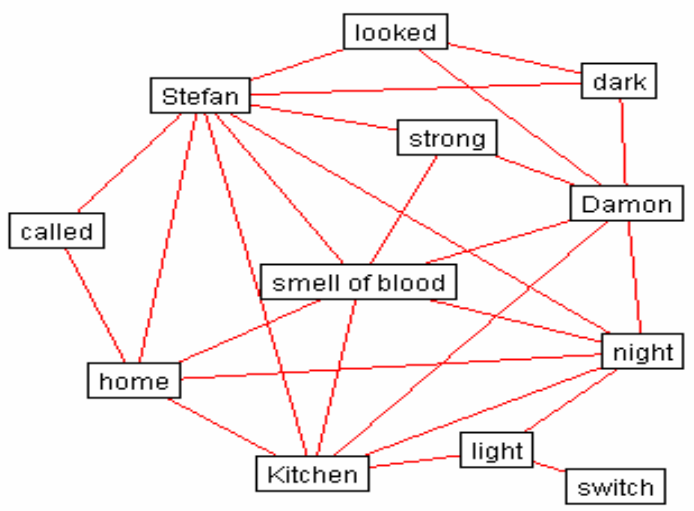

Figura 2 - Grafo gerado para uma fanfiction sobre o seriado Vampire Diaries

Quando executamos essa atividade de criação de grafos a partir de fanfictions, podemos notar um padrão de formação da imagem que tende a estar centrado justamente nestes elementos: a) tempo verbal; b) caracterização de personagens e contexto; c) relações entre os termos e a temática central. Desse modo, acredita-se que a ferramenta Rede de Conceitos seja um recurso auxiliador no processo inicial de produção de textos.

\section{Considerações Finais}

A principal contribuição deste trabalho é oportunizar uma reflexão acerca das possibilidades de promoção de letramento em língua estrangeira através de tarefas apoiadas por recursos tecnológicos que propiciem oportunidades de trabalho colaborativo. Desse modo, discutimos de que modo o ambiente digital pode ser um vetor potencializador da aprendizagem através de atividades apoiadas em ferramentas pedagógicas e digitais. Pensamos que tais propostas em ambiente digital podem fomentar a participação do aluno de modo ativo e autônomo na leitura e na produção, visto que os textos são produzidos conjuntamente. Assim, o papel participativo e autônomo do aluno pode ser enfatizado em tais tarefas, pois os aprendizes atuam como interlocutores reais dos textos dos colegas.

As ferramentas e metodologia propostas neste trabalho serão empregadas em um estudo mais amplo a ser realizado futuramente. O experimento será conduzido em uma turma de nível intermediário de inglês, com o objetivo de avaliar a metodologia aqui 
apresentada com um grupo maior de estudantes. Tal estudo permitirá melhor compreender as implicações da utilização das ferramentas SOBEK e ETC no letramento em língua estrangeira, bem como identificar novas necessidades e desdobramentos para a pesquisa.

\footnotetext{
${ }^{1}$ Gênero textual que engloba textos escritos por fãs de ícones culturais populares e midiáticos. Nessas composições há uma extensão da sinopse de um seriado, por exemplo, estabelecimentos de novas relações entre os personagens (BLACK, 2007) e ampliação de seqüências ou criação de uma história prévia para o objeto original.

${ }^{2} \mathrm{O}$ sistema permite utilizar uma lista chamada de stop-words com termos a serem desconsiderados do processo de mineração. Atualmente a ferramenta trabalha com listas de stop-words em português e em inglês, mas facilmente pode ser adaptada para outras línguas.

${ }^{3}$ Grafo baseado em excertos iniciais do texto Into the Fire, disponível em: <http://www.fanfiction.net//5844628/1/In_To_The_Fire> . Acesso em: 23 maio 2010.

${ }^{4}$ Informação disponível em: <http://www.nuted.edu.ufrgs.br/nuted/projeto_etc.html>. Acesso em: 19 maio 2010.
}

${ }^{5}$ Grafo baseado em excertos iniciais do texto $I$ see you, disponível em:< http://www.fanfiction.net/s/5974426/1/I_See_You> . Acesso em: 23 maio 2010.

\section{Referências Bibliográficas}

BEHAR, P. BITENCOURT, J.; MACEDO, A.; MAZZOCATO, S. Escrita coletiva: o potencial de um groupware via web. RENOTE - Revista Novas tecnologias na educação, Porto Alegre, v. 4, n. 1, 2006.

BLACK, R. Online fanfiction, global identities, and imagination. Research in the teaching of English, v. 43, n. 4, p. 397-425, 2009.

BLACK, R. Digital design: English language learners and reader reviews in online fanfiction. In: KNOBEL, M.; LANKSHEAR, C. (Ed.). A new literacies sampler. New York: Peter Lang Publishing, 2007. p. 115- 136.

BLACK, R. Language, culture, and identity in online fanfiction. E-Learning, v.3, n.2, p.170-184, 2006.

BROCH, I. Escrita coletiva de texto teatral em língua inglesa em ambiente virtual de aprendizagem: o foco do aluno no processo. Dissertação (Mestrado em Lingüística Aplicada) - Instituto de Letras, Universidade Federal do Rio Grande do Sul, Porto Alegre, 2008.

CLARK, H. O uso da linguagem. Cadernos de Tradução, n.9, p.49-71, jan-mar, 2000.

COSTA, J. Autoria coletiva em ambiente informatizado na perspectiva da formação de professores em língua inglesa. Tese (Doutorado em Informática na Educação) - Universidade Federal do Rio Grande do Sul, Porto Alegre, 2008.

FELDMAN, R., SANGER, J. Text Mining Handbook. Cambridge: Cambridge University Press, 2006.

GERALDI, J. (Org.). O texto na sala de aula. Cascavel: Assoeste, 1985.

JENKINS, H. Textual poachers: television, fans and participatory culture. New York: Routledge. 1992. 
KLEMANN, M.; LORENZATTI, A.; REATEGUI, E. O Emprego da Ferramenta de Mineração de Textos SOBEK como Apoio à Produção Textual. Simpósio Brasileiro de Informática na Educação, 2009, Florianópolis. Anais do SBIE, 2009.

LAM, W. L2 literacy and the design of the self: a case study of a teenager writing on the Internet. TESOL Quarterly, v.34, n.3, p.457-482, 2000.

LANKSHEAR, C.; KNOBEL, M. Sampling "the new” in new literacies. In: KNOBEL, M.; LANKSHEAR, C. (Ed.). A new literacies sampler. New York: Peter Lang Publishing, 2007. p. 1- 24.

MACEDO, A. Um recurso de apoio para acompanhamento da participação e contribuição do aluno na construção de textos coletivos. Tese (Doutorado em Informática na Educação) - Universidade Federal do Rio Grande do Sul, Porto Alegre, 2009.

MACEDO, A. ; REATEGUI, E. ; LORENZATTI, A.; BEHAR, P. Using text-mining to support the evaluation of texts produced collaboratively. Education and technology for a Better World: Selected papers of the $9^{\text {th }}$ World Conference on Computers in Education. Bento Gonçalves, Brasil, 2009.

MORAES, S.; KLEIMAN, A. Leitura e práticas disciplinares. In: MORAES, S.; KLEIMAN, A. Leitura e interdisciplinaridade: tecendo redes nos projetos da escola. São Paulo: Mercado de Letras, 1999.

PRENSKY, M. Digital natives, digital immigrants. In: PRENSKY, M. On the Horizon, v. 9, n. 5, 2001.

RAMAL, A. Educação na cibercultura: hipertextualidade, leitura, escrita e aprendizagem. Porto Alegre: Artmed, 2002.

SCHENKER, A. Graph-Theoretic Techniques for Web Content Mining. PhD thesis, University of South Florida, 2003.

SCHLATTER, M. O ensino de leitura em língua estrangeira na escola: uma proposta de letramento. Calidoscópio, v. 7, n.1, p.11-23, jan/abr, 2009.

SOARES, M. Português: uma proposta para o letramento. São Paulo: Moderna, 1999.

VEEN, W.; VRAKKING, B. Homo Zappiens: educando na era digital. Porto Alegre: Artmed, 2009.

WAQUIL, M.; BEHAR, P. Princípios da pesquisa científica para investigar ambientes virtuais de aprendizagem sob o ponto de vista do pensamento complexo. In: BEHAR, P.(Org.). Modelos pedagógicos em educação a distância. Porto Alegre: Artmed, 2008.

YI, Y. Relay writing in an adolescent online community. Journal of adolescent and adult literacy, v.51, p. 670-680, 2008. 